The flowers and fruit of the fossil are unknown, hence the exact affinities are still rather obscure. But the anatomical resemblances with Cyclanthus are set off by the arboreous habit of the plant which, as stated last year, "must have grown rooted in shallow water, with the stems rising in a clump, somewhat like those of a bamboo" 4 . These differences, coupled with the distance in time and space which separates the living and the extinct forms, suggests that the fossil should at least provisionally be referred to a new genus of the sub-family Cyclantheæ.

The generic name Cyclanthodendron is proposed. This new genus provides (like Rodeites) another interesting link between the Early Tertiary flora of the Deccan and the modern flora of South America.

$$
\text { B. SAHNI. }
$$

K. R. Surange.

Department of Botany and Geology,

University of Lucknow. April 19.

${ }^{1}$ Sahni, B., Curr. Sci., 3, 134 (1934). Proc. 24th Ind. Sci. Cong., 464 (1937). Inicknoto Univ. Studies, 2, 59 (1938). 27th Ind.' Sci.

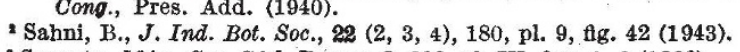

'Saporta, MÉm. Soc. Géol. France, 8, 338, pl. IV, flgs. 1, 3 (1868).

- Sahni, B., and Surange, Abs. Proc. Ind. Acad. Sci, and Nat. Acad. Sci. Hyderabad, 24 (1943).

sode, K. P., Quart. J. Geo. Min. and Met. Soc. India, 5 (3), 111 (1933).

\section{Unreleased Energy in Flame Gases}

WE recently reported ${ }^{1}$ the results of temperature measurements made by means of very fine quartzcoated platinum wires in the flame gases resulting from the combustion of hydrocarbon-air mixtures in a specially constructed burner. From these measurements estimates were made of the proportion of the heat of combustion which was unreleased in the flame gases for the purpose of increasing their temperature. The unreleased energy, we believe, is due partly to latent energy held in stable form in some of the newly formed tri-atomic molecules and partly to abnormal dissociation resulting therefrom. It varied from about 10 per cent to rather more than 20 per cent of the heat of combustion.
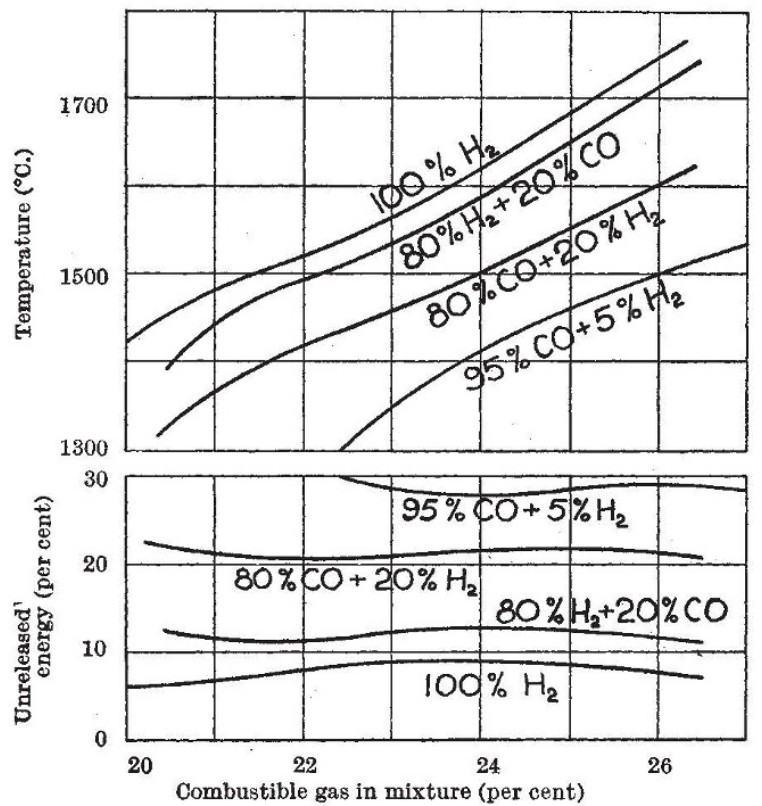

Similar measurements have since been made using mixtures of air with hydrogen and with carbon monoxide plus hydrogen in various proportions. The curves in the top portion of the accompanying graph show these measurements. It will be seen that for any given mixture strength the hydrogen flame gas temperature is more than $200^{\circ} \mathrm{C}$. higher than the carbon monoxide (with 5 per cent hydrogen) flame gas temperature-and this in spite of the fact that the calculated hydrogen flame gas temperatures are more than $100^{\circ} \mathrm{C}$. lower than the calculated carbon monoxide flame gas temperatures. The measured temperatures have not been corrected for radiation loss, but even after making full allowance for this, the hydrogen temperatures are of the order of $150^{\circ} \mathrm{C}$. below and the carbon monoxide (with 5 per cent hydrogen) temperatures of the order of $500^{\circ} \mathrm{C}$. below the corresponding calculated temperatures.

Curves giving estimates of the unreleased energy are shown in the lower portion of the graph. In the hydrogen flame gases this is of the order of 8 per cent of the heat of combustion and in the carbon monoxide (with 5 per cent hydrogen) flame gases it is nearly 30 per cent. There is little doubt that in flame gases resulting from the combustion of carbon monoxide with a much smaller proportion of hydrogen it would be considerably greater than 30 per cent.

W. T. DAVID.

Engineering Department,

$$
\text { J. MaNN. }
$$

The University,

Leeds.

June 9.

1 Phil. Mag., 34, 816 (1943).

\section{Rayleigh Quenching of Active Nitrogen}

ArIsrng out of work ${ }^{1}$ on the disappearance of the nitrogen afterglow by heating the activated gas at various pressures, it may be of interest to record results which indicate limits for the production of a like phenomenon observed by Lord Rayleigh ${ }^{2}$, namely, the quenching of the afterglow due to cooling by liquid air. With a condensed discharge in a Crookes' tube connected in series with a long glass spiral $S$, and a small bulb containing powdered iodine, the activated gas excited the characteristic iodine luminescence even when the afterglow in the observation spiral $S$ was feeble; both disappeared when $S$ was cooled by liquid air, in agreement with Rayleigh's observation $^{2}$. That this phenomenon is, however, restricted to low pressures is shown by the fact that when the gas pressure was increased progressively from $0.1 \mathrm{~mm}$. the Rayleigh quenching in $S$ tended to be less marked; was uncertain near $30 \mathrm{~mm}$. and not observed above $40 \mathrm{~mm}$.

A possibly insufficient cooling of the activated gas at high pressures was minimized as follows. The nitrogen was first streamed through a long spiral of glass, which enclosed the Crookes' tube; while both these were well immersed in a bath of liquid air, the gas was subjected to the discharge. A distinct afterglow was produced in $S$ even when it was cooled by liquid air, and was accompanied by luminescence in the iodine bulb. Both these effects were observed also at smaller pressures, at which under normal conditions (that is, when not cooled by liquid air before and during activation by the discharge) the Rayleigh quenching occurred. Addition of one more spiral cooled by liquid air, just before the one 